\title{
Assessment of wetland fragmentation in the middle reaches of the Heihe River by the type change tracker model
}

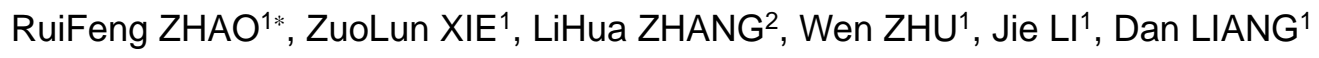 \\ ${ }^{1}$ College of Geography and Environment Science, Northwest Normal University, Lanzhou 730070, China; \\ ${ }^{2}$ Cold and Arid Regions Environmental and Engineering Research Institute, Chinese Academy of Sciences, Lanzhou 730000, China
}

\begin{abstract}
The quantitative research of wetland landscape fragmentation in the middle reaches of the Heihe River is important for the wetland and oasis sustainable development in the Hexi Corridor. Based on the data of remote sensing and GIS, we constructed the type change tracker model with sliding window technique and spatially morphological rule. The suitable scale and optimum scale of the fragmentation model of wetland landscape in the middle reaches of the Heihe River were determined by the area frequency statistics method, Chi-square distribution normalized scale variance, fractal dimension and diversity index. By integrating type change tracker model and the optimum scale with GIS spatial analysis, the spatial distribution characteristics of wetland landscape fragmentation in different periods and the related spatial-temporal change process were clarified. The results showed that (1) the type change tracker model, which analyzes the spatial pattern of wetland fragmentation on the pixel level, is better than the traditional wetland fragmentation analysis on the landscape and patch levels; (2) The suitable scale for the wetland fragmentation ranged from $150 \mathrm{~m} \times 150 \mathrm{~m}$ to $450 \mathrm{~m} \times 450 \mathrm{~m}$ and the optimum scale was $250 \mathrm{~m} \times 250 \mathrm{~m}$ in the middle reaches of the Heihe River; and (3) In the past 35 years, the total wetland area decreased by $23.2 \%$ and the fragmentation of wetland markedly increased in the middle reaches of the Heihe River. The areas of core wetlands reduced by $12.8 \%$ and the areas of perforated, edge and patch wetlands increased by $0.8 \%, 3.1 \%$ and $8.9 \%$, respectively. The process of wetland fragmentation in the research region showed the order of core wetland, perforated or edge wetland, patch wetland or non-wetland. The results of this study would provide a reference for the protection, utilization and restoration of limited wetland resources and for the sustainable development of the regional eco-environment in the Heihe River Basin.
\end{abstract}

Keywords: wetland; landscape pattern; fragmentation; the type change tracker model; Heihe River

Citation: RuiFeng ZHAO, ZuoLun XIE, LiHua ZHANG, Wen ZHU, Jie LI, Dan LIANG. 2015. Assessment of wetland fragmentation in the middle reaches of the Heihe River by the type change tracker model. Journal of Arid Land, 7(2): 177-188. doi: 10.1007/s40333-014-0047-Z

As a main body of the terrestrial ecosystem, wetland is one of the most biologically productive natural ecosystems on Earth (Nabahungu and Visser, 2011; van Roon, 2012). About $6 \%$ of the world's land surface was wetland which contributes up to $40 \%$ of the annual global ecosystem services (Costanza et al., 1997; Desta et al., 2012; Mereta et al., 2012). A wide variety of ecological functions such as nutrient cycling (Young et al., 2008), carbon storage (Mitsch et al., 2013), flood reduction (Zedler and Kercher, 2005) and habitat provision for wildlife (Lee et al., 2004) were performed by wetlands. Moreover, it is important in ensuring water supply, food security and livelihoods for millions of people living in developing countries (Teferi et al., 2010; Mereta et al., 2012). Due to considerable loss and significant fragmentation of wetlands over time, the decrease of biodiversity and the degradation of wetland ecosystem became more evident (Jenkins et al., 2012). Thus, quantifying wetland degradation has become a global research focus (Yang

\footnotetext{
"Corresponding author: RuiFeng ZHAO (E-mail: zhaoruifeng@126.com) Received 2014-05-01; revised 2014-11-10; accepted 2014-11-24

(C) Xinjiang Institute of Ecology and Geography, Chinese Academy of Sciences, Science Press and Springer-Verlag Berlin Heidelberg 2015
} 
et al., 2010; Song et al., 2011).

Ecological indicators have primarily been used to detect changes in nature in the past decades (Niemi and McDonald, 2004). Then the wetland condition model depending on plant-animal survey, water chemistry and soil property analysis was developed to detect the wetland degradation (Miller and Wardrop, 2006; Vorpahl et al., 2009; Deimeke et al., 2013). However, the sampling and test experiment for an extensive wetland degradation can be extremely time-consuming and expensive (Martínez-López et al., 2014). Researchers built time serial wetland data for detecting the degradation of regional wetlands in an effective manner (Nielsen et al., 2008). The dynamic degree model and centroid model were established to analyze the wetland change (Yue et al., 2003; Zhao et al., 2009; Wen et al., 2011; Zhang et al., 2011), but these methods applied the vector algorithm and failed to combine raster data effectively. Most of the landscape pattern indices also lack spatial information and fragmentation process (Wang et al., 2011; Jiang et al., 2013). Additionally, Cellular Automata (CA) model can't describe the fragmentation between different wetland fragmentation types (Zhang et al., 2009). The sliding window technique was first applied in the landscape fragmentation analysis by Riitters et al. (2000). Then extensive studies have been carried out in forest fragmentation on the country and global scales (Riitters et al., 2002; Wade et al., 2003; Li et al., 2011), and the method displayed advantage relative to traditional landscape index (Vogt et al., 2007). However, the fragmentation research of wetland landscape using sliding window technique has seldom been reported so far, and didn't focus on the suitable and optimum scale for the models.

Riparian wetland in arid region is particularly important for the oasis ecosystems (Zhou et al., 2006). The health of wetland in the middle reaches of the Heihe River is important for the biodiversity conservation and oasis development in the Hexi Corridor. Most previous studies in the Heihe River mainly focused on water resources exploitation, relationships between local economic development and water resource management, and ecological consequences of water resources over-exploitation (Fang et al., 2007; Wang et al., 2007; Zhu et al., 2008). The patterns and fragmentation of riparian wetlands using the method of landscape pattern index have been reported in the Heihe River Basin ( $\mathrm{Li}$ and Zhao, 2010; Jiang et al., 2013). However, the spatial and quantitative characteristics of the fragmentation process in the region were not clear. Thus, our aims are to (1) construct the fragmentation model based on the sliding window technique, spatially morphological rule and GIS tool; (2) determine the suitable scale and optimum scale of the fragmentation model of wetland landscape in the middle reaches of the Heihe River; and (3) clarify the spatial distribution characteristics and temporal dynamics of wetland fragmentation.

\section{Materials and methods}

\subsection{Study area}

The Heihe River originates from the Qilian Mountains, flows through the Hexi Corridor of Gansu province and enters into the western part of the Inner Mongolia Plateau. It is the second largest inland river basin in China with an area of $1.16 \times 10^{5} \mathrm{~km}^{2}$. The main stream length is $821 \mathrm{~km}$ with a mean runoff of $28 \times 10^{9} \mathrm{~m}^{3} / \mathrm{a}$ (Chen et al., 2005). The location of the middle reaches of the Heihe River is between $96^{\circ} 42^{\prime}-102^{\circ} 00^{\prime} \mathrm{E}$ and $37^{\circ} 41^{\prime}-42^{\circ} 42^{\prime} \mathrm{N}$. The average annual precipitation is 100-350 mm, average annual evaporation 1,600 $2,400 \mathrm{~mm}$, annual mean temperature $3.4^{\circ} \mathrm{C}-8.0^{\circ} \mathrm{C}$, annual sunshine duration 2,700-3,200 $\mathrm{h}$ and annual global radiation 133.36-148.42 $\mathrm{MJ} / \mathrm{m}^{2}$ (Zhao et al., 2005). Zonal soil types in the area include gray-brown desert soil and gray desert soil. The vegetation is temperate dwarf shrub and sub-shrub.

In the region, there are some important events (as time nodes) during the research period. In 1987, the implementation of constructing of commodity grain base in the Hexi Corridor (1988-1992) promoted the agricultural development. The East Juyanhai Lake, a terminal lake of the Heihe River, dried up since 1992. At the same time, a water diversion project was put forward by the Sate Council. In 2001, the water from the Heihe River reached the East Juyanhai Lake drying up for ten years by trans-provincial water diversion. Therefore, we classified the study time as the following four periods according to the above time nodes, and they were 1975-1987, 1987-1992, 1992-2001 and 
2001-2010, respectively.

\subsection{Data sources, image interpretation and field survey}

Landsat satellite data including Multispectral Scanner (MSS), Thematic Mapper (TM) and Enhanced Thematic Mapper Plus (ETM+) across five time periods, with less than $10 \%$ cloud cover were selected for detecting the land cover map. For avoiding the impacts of season, we selected the images from July to October (Table 1). Images were corrected for geometric distortion (Lasanta and Vicente-Serrano, 2012), in the ERDAS IMAGINE 9.2. The MSS and TM data were geometrically rectified by selecting ground control points and projected into Krasovsky_1940 coordinates. For reducing the error caused by different resolution, we resampled MSS images to a $30 \mathrm{~m} \times 30 \mathrm{~m}$ pixel size using the cubic convolution algorithm. The root mean square error (RMSE) among the control points selected on the ground was less than $1 \mathrm{~m}$ and that the final geometric matching error among these images was within one pixel through visual examination.

We classified the landscape types as six categories based on the land-use classification system (Shalaby, 2007), including grassland, arable land, forest, wetland, construction land and bare land. The interpretation depends on the color composites (Wilson and Sader, 2002). It was necessary to test the TM interpretation precision with the field survey data for determining the accuracy of visual interpretation.

For assisting the interpretation, we sampled 77 field survey plots along the river course using GPS, and sampled 85 accuracy assessment plots in the study area through Google Earth in the summer of 2011 (Fig. 1). The vegetation cover, groundwater and soil property were surveyed for testing the accuracy of the interpretation. According to the field work, topographic maps and Google Earth data, the interpretation precisions were respectively $77.67 \%$ (1975), $80.74 \%$

Table 1 Data sources for landscape information of the study area

\begin{tabular}{ccl}
\hline Year & Data source & Path/Raw times (dd-mm-yy) \\
\hline 1975 & MSS & $143 / 33,07-10-1975 ; 145 / 32,09-10-1975 ; 144 / 33,04-07-1976$ \\
1987 & TM & $133 / 33,15-08-1987 ; 134 / 33,09-10-1987 ; 134 / 32,28-09-1989$ \\
1992 & TM & $133 / 33,05-09-1992 ; 134 / 33,27-08-1992 ; 134 / 32,02-09-1991$ \\
2001 & ETM & $133 / 33,07-07-1999 ; 134 / 33,03-07-2001 ; 134 / 32,20-08-2001$ \\
2010 & ETM & $133 / 33,14-08-2010 ; 134 / 33,05-08-2010 ; 134 / 32,21-08-2010$ \\
\hline
\end{tabular}

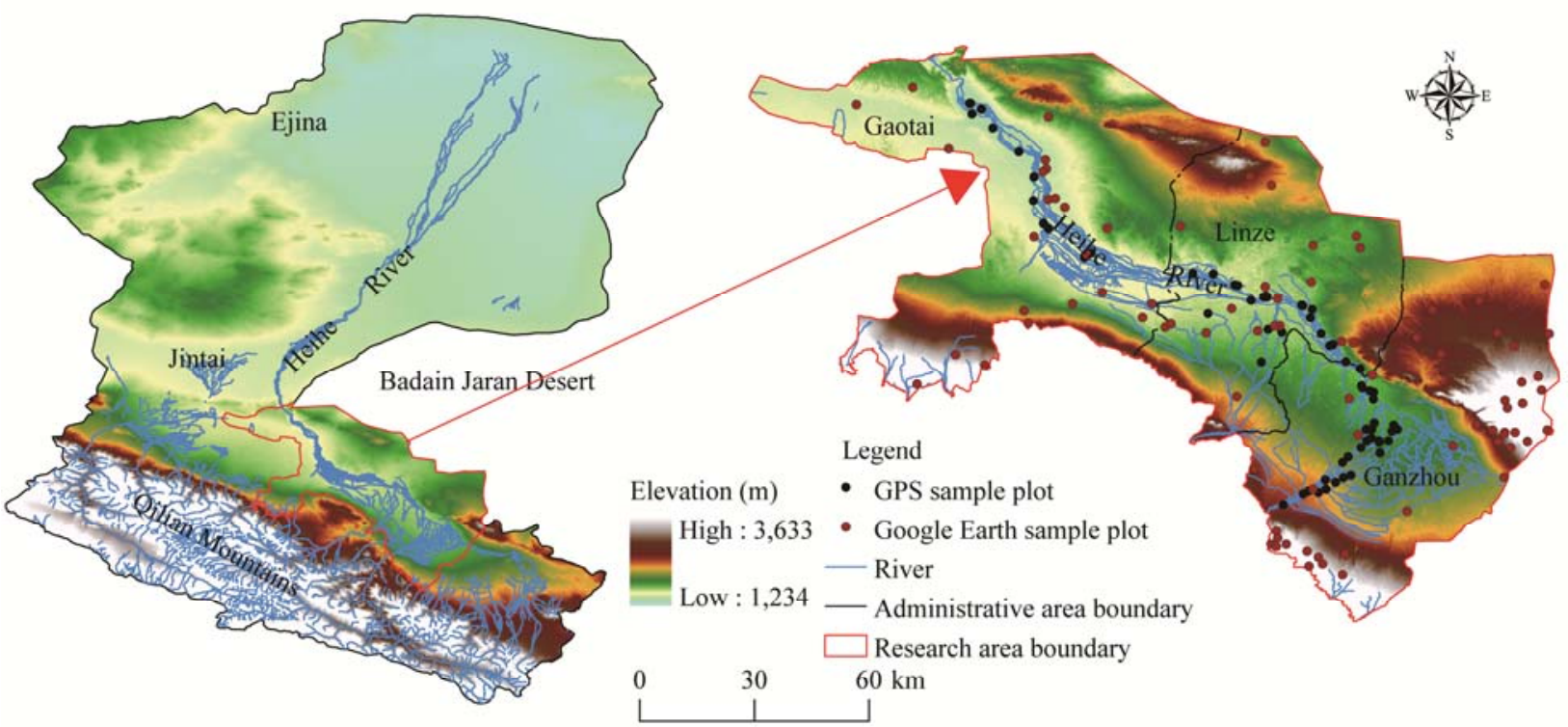

Fig. 1 Location of the study area in the Heihe River basin 
(1987), 77.92\% (1992), 80.57\% (2001) and 81.18\% (2010) by the positional accuracy evaluation.

\subsection{Methods}

1.3.1 Building the binary wetland map

A raster land-cover map with $50 \mathrm{~m}$ pixel size was converted from the land-cover vector data which were collected from satellite images. The land-cover type was aggregated to focus on the pattern of wetland versus non-wetland.

\subsubsection{Type change tracker model}

The purpose of the type change tracker model is to generate a map that would allow a user to visualize and quantify the extent of wetland fragmentation and track the change in fragmentation over time. The model was developed from the sliding window technique and spatially morphological rule in the forest fragmentation models developed by Riitters et al. (2000) and Vogt et al. (2007). The model used a sliding-window algorithm with overlapping windows to calculate two metrics and store them at the location of the center pixel. The two metrics were used to classify the wetland fragmentation type for every grid (Table 2). In Table 2, $\mathrm{P}_{\mathrm{w}}$ is the percentage of wetland pixels within the algorithm window; $\mathrm{P}_{\mathrm{ww}}$ is calculated by the number of grid cell pairs where both grid cells were divided by the total number of wetland grid cell pairs that have at least one wetland grid cell. A higher connectivity between wetland grids cells was indicated by high $\mathrm{P}_{\mathrm{ww}}$ values. The identification of the four fragmentation types depending on the values of $\mathrm{P}_{\mathrm{w}}$ and $\mathrm{P}_{\mathrm{ww}}$ was shown in Table 2. Meanwhile, the spatially morphological characteristics of four types of wetland fragmentation were shown in Fig. 2.

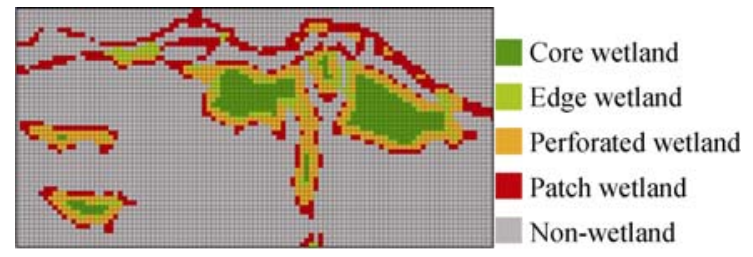

Fig. 2 Illustration of four types of wetland fragmentation

Table 2 Definition of wetland fragmentation types

\begin{tabular}{|c|c|c|c|}
\hline Fragmentation type & Fragmentation characteristic & Fragmentation degree & Metric* \\
\hline Core wetland & All pixels within the analysis window are wetland & Wetland fragmentation did not occur & $\mathrm{P}_{\mathrm{w}}=\mathrm{P}_{\mathrm{ww}}=1$ \\
\hline Edge wetland & $\begin{array}{l}\text { Most of the pixels within the analysis window are wetland, but } \\
\text { some appear to be part of the outside edge of wetland }\end{array}$ & $\begin{array}{l}\text { Wetland fragmentation occurred but } \\
\text { not serious }\end{array}$ & $\begin{array}{l}\mathrm{P}_{\mathrm{w}}>0.6 \text { and } \\
\mathrm{P}_{\mathrm{w}}-\mathrm{P}_{\mathrm{ww}}<0\end{array}$ \\
\hline Perforated wetland & $\begin{array}{l}\text { Most of the pixels within the analysis window are wetland, but } \\
\text { some appear to be part of the inside edge of a wetland patch }\end{array}$ & $\begin{array}{l}\text { Wetland fragmentation occurred but } \\
\text { not serious }\end{array}$ & $\begin{array}{l}\mathrm{P}_{\mathrm{w}}>0.6 \text { and } \\
\mathrm{P}_{\mathrm{w}}-\mathrm{P}_{\mathrm{ww}}>0\end{array}$ \\
\hline Patch wetland & $\begin{array}{l}\text { Very few wetland pixels that are part of a wetland patch on a } \\
\text { non-wetland background }\end{array}$ & $\begin{array}{l}\text { A serious wetland fragmentation } \\
\text { occurred }\end{array}$ & $\mathrm{P}_{\mathrm{w}} \leq 0.6$ \\
\hline
\end{tabular}

Note: *, the metrics were cited from the references of Riitters et al. (2000) and Vogt et al. (2007).

\subsubsection{Scale}

Owing to the strip distribution of inland river wetland that is different from the vast tracts for forest, it is important to minimize the edge effect and determine the suitable scale and optimum scale for wetland fragmentation research using the type change tracker model. The traditional normalized scale variance analysis is inefficient for inland river wetland due to the strip distribution. Thus, the possible suitable scale is determined by the analysis of area frequency and area-weighted mean patch fractal dimension (AWMPFD). We calculated the normalized scale variance based on chi-square distribution (Chi-NSV) and the credibility to ascertain the suitable scale. We choose the optimum scale basing on the result of sensitive analysis of Chi-NSV and Shannon's Diversity Index.

(1) Area-weighted mean patch fractal dimension (AWMPFD)

The fractal dimension usually describes the complexity and the fragmentation of a patch by a perimeter area proportion, which has been widely used in geomorphology, hydrology, ecology and other spatial pattern analysis. The fractal dimension values range between 1 and 2 . The more complex and fragmented, the perimeter increases, a higher fractal dimension yields (Herold et al., 2002). The area-weighted mean patch fractal dimension (AWMPFD) was calculated to find a particular scale domain which can help us to find the self-similarity in this scale domain (Zhao et al., 2009). AWMPFD can be calculated by the fol- 
lowing equation:

$$
A W M P F D=\sum_{i=1}^{m} \sum_{j=1}^{n}\left(\frac{2 \ln \left(0.25 p_{i j}\right)}{\ln a_{i j}} \times \frac{a_{i j}}{A}\right) .
$$

Where $m$ is the number of patch types (classes), $n$ is the number of patches of a class, $p_{i j}$ is the perimeter of patch $i j, a_{i j}$ is the area of patch $i j, A$ is total landscape area.

(2) Normalized scale variance based on Chi-square distribution (Chi-NSV)

The scale variance analysis was first developed by Moellering and Tobler (1972). Generally, the scale variance is a spatial hierarchical method, which is similar to semi-variance and spatial autocorrelation analysis. Nested data hierarchies (spatial grain sizes increase with $2 n$ of $22 n, n=0,1,2 \ldots$ ) were required in the scale variance analysis (Townshend and Justice, 1990). The quantity was inconformity to the nested data hierarchies. We developed a new normalized scale variance based on the Chi-square distribution to calculate the scale variance (Shen et al., 2008; Zhao et al., 2009). This scale variance analysis was named Chi-NSV which can be calculated by the following equation:

$$
\begin{gathered}
\chi_{j}=\frac{\left(n_{j}-1\right) S_{j}^{2}}{\sigma^{2}}, \\
\sigma^{2}=\frac{1}{m} \sum_{i=1}^{m}\left(Y_{i}-E(Y)\right)^{2}, \\
S_{j}^{2}=\frac{1}{n_{j}-1} \sum_{i=1}^{n_{j}}\left(X_{i j}-E\left(X_{j}\right)\right)^{2} .
\end{gathered}
$$

Where $\chi_{j}$ is the Chi-NSV value of type $j$ wetland, $S_{j}^{2}$ is the variance of type $j$ wetland, $j=1,2,3,4$ represented core wetland, perforated wetland, edge wetland and patch wetland, $n_{j}$ is the number of type $j$ wetland, $\sigma^{2}$ is the variance of all wetland patch, $Y_{i}$ is the area of patch $i, m$ is the number of wetland patch, $X_{i j}$ is the area of patch $i j, E\left(X_{j}\right)$ is the mathematical expectation of type $j$ wetland. $\chi_{j}$ obeys the Chi-square distribution and it is monotonic decreasing function in the domain if the degrees of freedom $k \leq 2$. It suggests that the suitable scale does not appear in the pixel of $50 \mathrm{~m}$. Otherwise, the function shows right skewed and the maximum value is the suitable scale. The Chi-NSV value was normalized, indicating the result better.

(3) The credibility for suitable scale
The credibility for a suitable scale is one of the important indices to test the rightness. It was the interval probability for the suitable scale which can be calculated by the following equation (Shen at al., 2008):

$$
P(a \leq x \leq b)=\frac{\int_{a}^{b} f(x) d x}{\int_{0}^{+\infty} f(x) d x} .
$$

Where $P(a \leq \mathrm{x} \leq b)$ is the credibility of the suitable scale $(a \times a-b \times b) . f(x)$ is the function of Chi-NSV for different wetland types.

(4) Shannon's diversity index $(\mathrm{H})$

The diversity index was developed to measure the complexity of system structure. Shannon-Weaver diversity index was used to detect the optimum scale for the type change tracker model. The index value was related to the number and evenness degree in quantity of different types (Wu et al., 2002).

$$
H=-\sum_{k=1}^{n} p_{k} \ln \left(p_{k}\right) .
$$

Where $p_{k}$ is the proportion of the $k_{t h}$ wetland area to the total wetland area, and $n$ is the number of wetland types.

\section{Results}

\subsection{The suitable scale and optimum scale}

Area frequency of different wetlands fragmentation types under different scales in the middle reaches of the Heihe River in 2010 was shown in Fig. 3. With the increasing windows scale, the area of core and perforated wetlands decreased, and that of the patch wetlands increased. For the edge wetland the largest area frequency appeared in the scale of $5 \times 5$ pixels. The core wetland disappeared when the windows scale is larger than $25 \times 25$ pixels. The suitable scale of the type change tracker model should be smaller than $25 \times 25$ pixels. The anomaly of AWMPFD was shown in Fig. 4. The scale domain for the AWMPFD was between $3 \times 3$ pixels and $25 \times 25$ pixels. The possible suitable sale for the type change tracker model ranges from $3 \times 3$ pixels to $25 \times 25$ pixels.

The distribution of Chi-NSV is right-skewed, which means that the suitable scale exists (Fig. 5). The suitable 


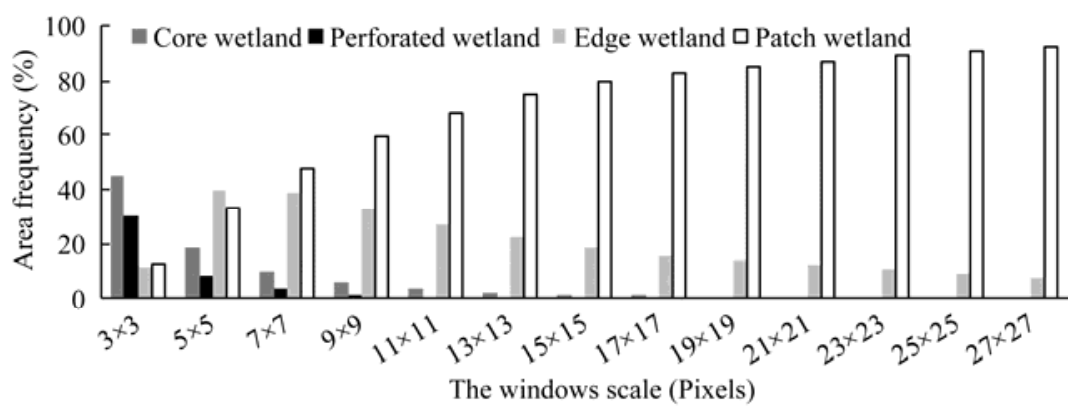

Fig. 3 Area frequency of different wetlands fragmentation types under different scales in the middle reaches of the Heihe River

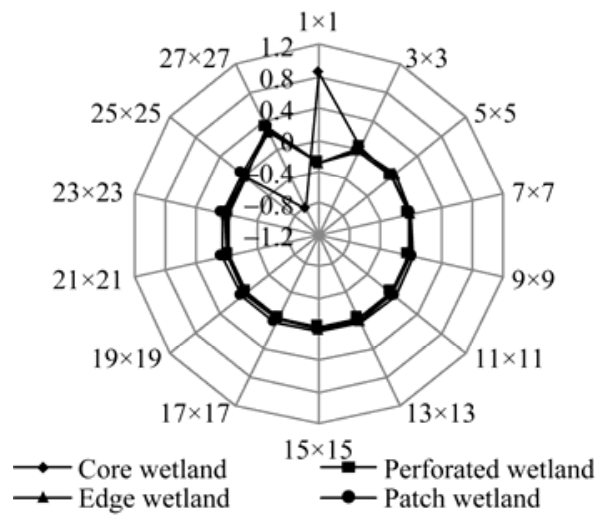

Fig. 4 The anomaly of area-weighted mean patch fractal dimension

scale was selected in the pixel of $50 \mathrm{~m}$. It is possible that the suitable scale is a threshold (an inflection point) or a scale domain. Chi-NSV value showed that inflection points for core wetland and perforated wetlands were $3 \times 3$ pixels. The scales of $5 \times 5$ pixels and $9 \times 9$ pixels were the inflection points for edge wetlands and patch wetlands, respectively. The suitable scale for the type change tracker model ranged from $3 \times 3$ pixels to $9 \times 9$ pixels.

The credibility of suitable scales was displayed as credibility value. The interpretation of credibility values in mathematical statistics is: credibility values $=100 \%$, perfect; credibility values $\geq 75 \%$, excellent; $40 \% \leq$ credibility values $\leq 75 \%$, fair to good; credibility values $\leq 40 \%$, poor (Pontius, 2002; Fleiss et al., 2003). The credibility values for core, perforated and edge wetlands ranged from $57.1 \%$ to $85.4 \%$. The poor credibility $(22.1 \%)$ for patch wetland may be related to its special data hierarchy.

The sensitivity of Chi-NSV value decreased with the increasing scale (Fig. 6). When the window scale increased from $3 \times 3$ pixels to $5 \times 5$ pixels and from $5 \times 5$ pixels to $7 \times 7$ pixels, the Chi-NSV sensitivity changed fast except for the patch wetland. Meanwhile, the Shannon diversity index $(\mathrm{H})$ was largest at the $5 \times 5$ pixels scale (Table 3 ). Combing Chi-NSV sensitivity analysis with $\mathrm{H}$ index, $5 \times 5$ pixels should be the optimum window scale.

\subsection{Wetland fragmentation in the middle reaches of the Heihe River}

2.2.1 The area changes of different wetland fragmentation types

The wetland area in the middle reaches of the Heihe River reduced by $7,570 \mathrm{hm}^{2}$ between 1975 and 2010 (Table 4). The area change experienced a process of rapid decline-slow increase-slow decrease-fast decline in the research period. The decreased rate of wetland area was $404 \mathrm{hm}^{2} /$ a during 1975-1987, 93 $\mathrm{hm}^{2} /$ a during 1987-1992, $57 \mathrm{hm}^{2} /$ a during 1992-2001 and $297 \mathrm{hm}^{2} /$ a during 2001-2010.

Among the four fragmentation types, the percentage of edge wetland was the greatest, $36.9 \%$ to $40.5 \%$ during the period of $1975-2010,24.4 \%$ to $33.2 \%$ for patch wetland, $31.5 \%$ to $18.8 \%$ for core wetland and smallest for perforated wetland (around $8 \%$ ) (Table 4). The area of core wetland changed most sharply between 1975 and 2010, reducing by $12.7 \%$.

The decrease of core wetland area mainly occurred in the periods of 1975 to 1987 and 2001 to 2010, with slow increase of $256 \mathrm{hm}^{2}$ from 1987 to 2001 . The area of edge and perforated wetlands respectively decreased 2,016 and $347 \mathrm{hm}^{2}$, while the percentage of edge and perforated wetlands respectively increased by $3.1 \%$ and $0.8 \%$ between 1975 and 2010 . Except for the period from 1987 to 1992 , the area of edge wetland decreased continuously. The perforated wetland area decreased except for the period of 1992 to 2001. The patch wetland area increased 


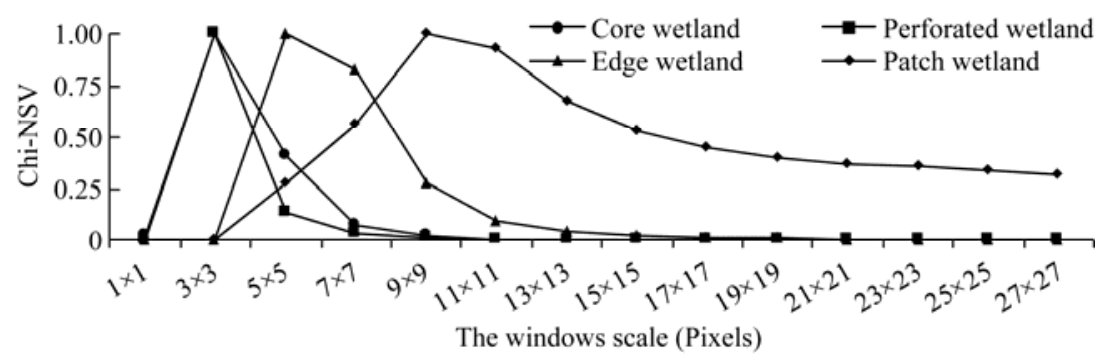

Fig. 5 Chi-NSV (Chi-square distribution normalized scale variance) value under different windows scales

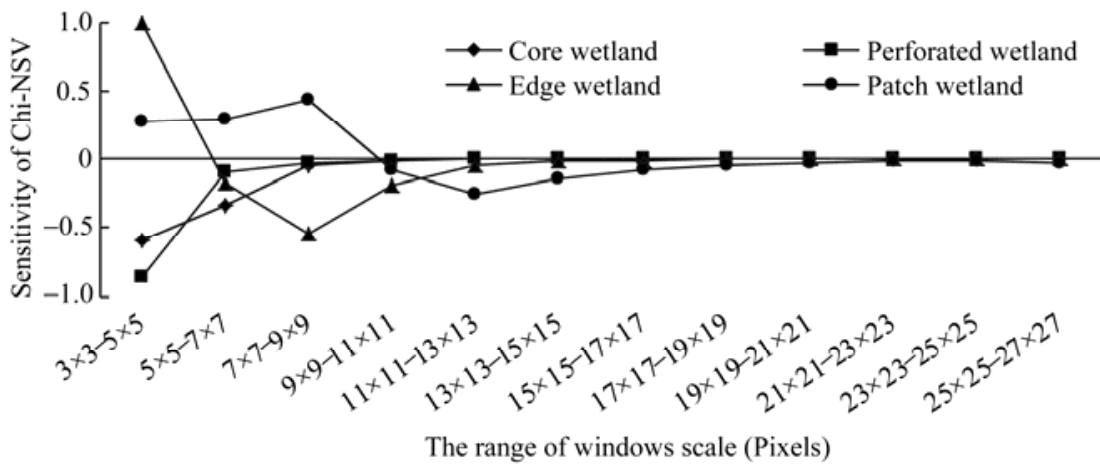

Fig. 6 The sensitivity analysis of Chi-NSV (Chi-square distribution normalized scale variance)

Table 3 The Shannon's diversity index $(\mathrm{H})$ under different windows scales

\begin{tabular}{|c|c|c|c|c|c|}
\hline $\begin{array}{c}\text { Scale } \\
\text { (Pixels) }\end{array}$ & $H$ & $\begin{array}{c}\text { Scale } \\
\text { (Pixels) }\end{array}$ & $H$ & $\begin{array}{c}\text { Scale } \\
\text { (Pixels) }\end{array}$ & $H$ \\
\hline $1 \times 1$ & 0.0000 & $11 \times 11$ & 0.1289 & $21 \times 21$ & 0.1204 \\
\hline $3 \times 3$ & 0.1396 & $13 \times 13$ & 0.1263 & $23 \times 23$ & 0.1193 \\
\hline $5 \times 5$ & 0.1399 & $15 \times 15$ & 0.1241 & $25 \times 25$ & 0.1181 \\
\hline $7 \times 7$ & 0.1355 & $17 \times 17$ & 0.1226 & $27 \times 27$ & 0.1172 \\
\hline $9 \times 9$ & 0.1319 & $19 \times 19$ & 0.1214 & - & - \\
\hline
\end{tabular}

by $376 \mathrm{hm}^{2}$ and $8.9 \%$ between 1975 and 2010, with a continuous increase $\left(741 \mathrm{hm}^{2}\right)$ from 1992 to 2010 .

2.2.2 The spatial changes of different wetland fragmentation types

Table 5 showed the matrices of wetland fragmentation type transition in different periods, and the changed map was shown in Fig. 7. During the period of 1975-1987, about $25.5 \%$ of core wetlands, $25.3 \%$ of perforated wetlands, $22.3 \%$ of edge wetlands and $23.3 \%$ of patch wetlands were transformed into non-wetlands. Lots of core wetlands were converted to edge wetlands and perforated wetlands. Meanwhile, a certain number of perforated wetlands and edge wetlands changed to patch wetland. However, very little of non-wetlands was converted into core wetlands, perforated wetlands, edge wetlands and patch wetlands. The transformation trends among wetland fragmentation types and non-wetlands in the periods of 1987-1992, 1992-2001 and 2001-2010 were similar to that during 1975-1987. As a whole, larger areas of the core wetlands mainly transformed to non-wetlands and edge wetlands, a certain number of edge wetlands and perforated wetlands were transformed to patch wetland, and quite a number of patch wetlands transformed to non-wetlands.

Table 4 Areas of different wetlands fragmentation types in the middle reaches of the Heihe River

\begin{tabular}{|c|c|c|c|c|c|c|c|c|}
\hline \multirow{2}{*}{ Year } & \multicolumn{2}{|c|}{ Core wetland } & \multicolumn{2}{|c|}{ Perforated wetland } & \multicolumn{2}{|c|}{ Edge wetland } & \multicolumn{2}{|c|}{ Patch wetland } \\
\hline & Area $\left(\mathrm{hm}^{2}\right)$ & Percentage $(\%)$ & Area $\left(\mathrm{hm}^{2}\right)$ & Percentage $(\%)$ & Area $\left(\mathrm{hm}^{2}\right)$ & Percentage $(\%)$ & Area $\left(\mathrm{hm}^{2}\right)$ & Percentage (\%) \\
\hline 1975 & 10,297 & 31.5 & 2,363 & 7.2 & 12,034 & 36.9 & 7,950 & 24.4 \\
\hline 1987 & 7,105 & 25.6 & 2,180 & 7.8 & 10,780 & 38.8 & 7,734 & 27.8 \\
\hline 1992 & 7,209 & 25.5 & 2,017 & 7.1 & 11,451 & 40.5 & 7,585 & 26.8 \\
\hline 2001 & 7,361 & 26.5 & 2,043 & 7.4 & 10,717 & 38.6 & 7,626 & 27.5 \\
\hline 2010 & 4,714 & 18.8 & 2,016 & 8.0 & 10,017 & 40.0 & 8,326 & 33.2 \\
\hline
\end{tabular}


Table 5 Transition matrix of different wetland fragmentation types in the middle reaches of the Heihe River

\begin{tabular}{rcrrrrr}
\hline \multirow{2}{*}{ Period } & Fragmentation type & Core wetland & Perforated wetland & Edge wetland & Patch wetland & Non-wetland \\
\cline { 2 - 6 } & & & & $\left(\mathrm{hm}^{2}\right)$ & & \\
& Core wetland & 5,491 & 491 & 1,254 & 431 & 2,630 \\
& Perforated wetland & 243 & 1,131 & 268 & 123 & 599 \\
& Edge wetland & 575 & 269 & 7,939 & 567 & 2,684 \\
& Patch wetland & 125 & 66 & 342 & 5,565 & 1,852 \\
& Non-wetland & 672 & 223 & 979 & 1,048 & $1,039,822$ \\
& Core wetland & 4,661 & 259 & 725 & 231 & 1,229 \\
$1987-1992$ & Perforated wetland & 331 & 1,077 & 303 & 80 & 389 \\
& Edge wetland & 792 & 245 & 7,926 & 394 & 1,424 \\
& Patch wetland & 214 & 100 & 557 & 5,400 & 1,462 \\
& Non-wetland & 1,211 & 335 & 1,940 & 1,481 & $1,042,620$ \\
& Core wetland & 5,205 & 242 & 634 & 224 & 904 \\
& Perforated wetland & 225 & 1,151 & 229 & 92 & 320 \\
& Edge wetland & 615 & 241 & 8,259 & 580 & 1,757 \\
& Patch wetland & 195 & 68 & 333 & 5,610 & 1,380 \\
& Non-wetland & 1,122 & 342 & 1,261 & 1,121 & $1,043,279$ \\
& Core wetland & 3,157 & 511 & 1,202 & 426 & 2,065 \\
& Perforated wetland & 109 & 916 & 229 & 149 & 640 \\
& Edge wetland & 282 & 216 & 7,052 & 730 & 2,436 \\
& Patch wetland & 119 & 52 & 292 & 5,277 & 1,887 \\
& Non-wetland & 1,047 & 320 & 1,244 & 1,743 & $1,043,286$ \\
\hline
\end{tabular}

Note: Wetland fragmentation types listed horizontally in the table represent initial statuses and vertically listed wetland fragmentation types represent the statuses after transition.
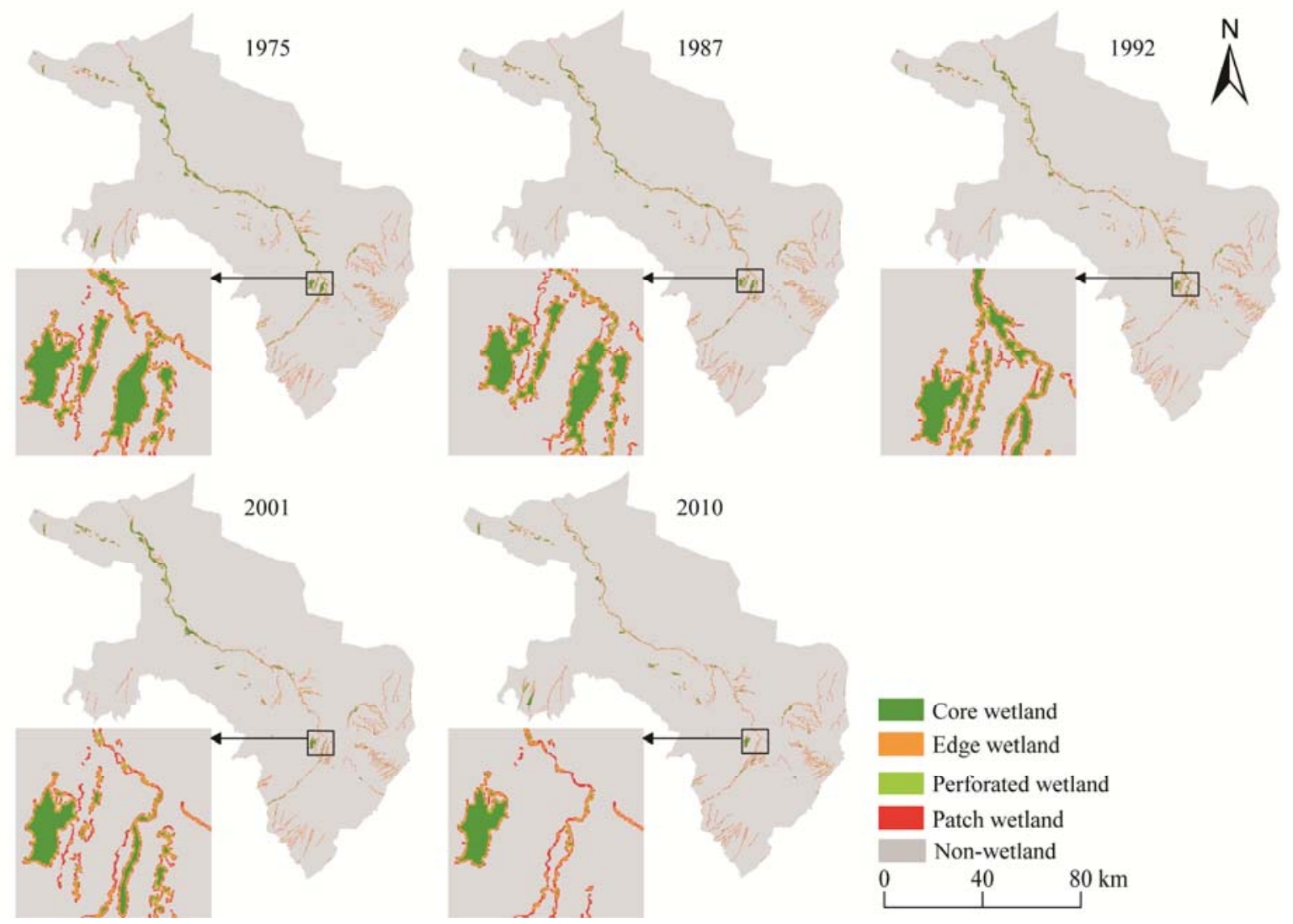

Core wetland

Edge wetland

Perforated wetland

Patch wetland

Non-wetland

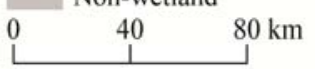

Fig. 7 Changes of derived wetland fragmentation in the middle reaches of the Heihe River based on an analysis window of the $5 \times 5$ pixels $(250 \mathrm{~m} \times 250 \mathrm{~m})$ 


\section{Discussion}

\subsection{The type change tracker model}

The type change tracker model performed well in the analysis of wetland fragmentation in the middle reaches of the Heihe River. The wetland fragmentation represented the conversion of two types, the conversion between wetland and non-wetland and conversion among wetland fragmentation types (that is, core wetland, perforated wetland, edge wetland and patch wetland). The wetland area in the middle reaches of the Heihe River reduced by $7,570 \mathrm{hm}^{2}$ between 1975 and 2010. The edge wetland was the main fragmentation type, with increasing percentage of $36.9 \%$ to $40.5 \%$ in the study periods. Patch wetland was in second $(24.4 \%-33.2 \%)$. The area proportion of core wetland decreased from $31.5 \%$ to $18.8 \%$ and perforated wetland had the smallest area (around $8 \%$ ). It indicates that the results from type change tracker model are more concrete and abundant in spatial information and fragmentation processes than that the traditional wetland fragmentation analysis.

Most of the landscape pattern indices (e.g. Number of Patches, Proportion of Landscape and Largest Patch Index) are related with the geometric characteristics of patch, the specific fragmentation process could not be clarified in lack of clear space and position significance (Wang et al., 2011; Jiang et al., 2013). The area change and rate of different wetland types can be determined by the dynamic degree model, but it is incapable to analyze the spatially fragmentation process. The centroid model used to detect the direction of wetland degradation (Yue et al., 2003; Zhao et al., 2009; Zhang et al., 2011) also could not reveal the fragmentation in the wetland interior. The CA model could be used to simulate and forecast the changing process of wetland landscape pattern in the pixel level, but it is insufficient for land type in variable state and transformation among wetland types (Zhang et al., 2009). The river wetland in arid region is susceptible to the influence of anthropogenic activity, flood and drought and results in the change of other wetland types along the river course, which is the main source of the error for CA model (Zheng et al., 2010).

\subsection{The suitable scale and optimum scale}

Scale effect was used in landscape pattern research (Montgomery and Dietrich, 1992), and is the basis for wetland fragmentation model. Scale variance is one of the methods of multi-scale analysis, and nested hierarchies need to be characteristic of patches under different scales (Townshend and Justice, 1990). However, traditionally normalized scale variance analysis was inefficient due to the strip distribution of inland river wetland in arid region (Zhao et al., 2009). In the present study, Chi-NSV was established to adapt the particular data hierarchy of wetland and accomplish the normalization of scale variance (Shen et al., 2008). Civco et al. (2002) used the scale of $150 \mathrm{~m} \times 150 \mathrm{~m}$ in the forest fragmentation research in Northeast America according to the size of smallest forest patch. The main wetland type of the study is river wetland and beaches wetland in the middle reaches of the Heihe River. With increasing windows size, the width of edge effect increased, the core wetland area decreased and the area of edge wetland increased. With continuous increase of windows size, the area of edge wetland also decreased (Li et al., 2011). The result suggested that the suitable window size should be smaller than the window size at which edge wetland area decreased fast. The edge wetland decreased faster when the windows size increased from $350 \mathrm{~m} \times 350 \mathrm{~m}$ to 450 $\mathrm{m} \times 450 \mathrm{~m}$ (Fig. 4), and thus, the suitable scale is 150 $\mathrm{m} \times 150 \mathrm{~m}-450 \mathrm{~m} \times 450 \mathrm{~m}$ for the wetland fragmentation in the middle reaches of the Heihe River. The credibility analysis of suitable scales also indicated the results were feasible.

When the model was applied into the wetland fragmentation analysis in the middle reaches of the Heihe River, it is not rational to select the window scale according to the smallest wetland patch shape. Taking into account the strip distribution of wetland in the study area, the edge effect should depend on the mean width of the wetland patch. The relationship between the windows size and the effect size is that, the effect edge is $1+(n-1) / 2$ when the window size is $n$ pixel (Riitters et al., 2002). According to the shape of wetland in the middle reaches of the Heihe River, the mean width was equal to the ratio of total area to one half of total perimeter. The mean width of total wetland patches was $155.99 \mathrm{~m}$, which suggested the edge 
effect width was close to 3 pixels. It corresponded to the window size of 5 pixels, and then the optimum scale should be $250 \mathrm{~m} \times 250 \mathrm{~m}$. In the present study, the optimum scale for the type change tracker model was determined at $50 \mathrm{~m}$ pixel owing to limited data. The pixel precision limitation could lead to the error of scale determination. In future, the optimum scale would be tested at smaller pixel if higher resolution data could be got.

\subsection{The wetland fragmentation in the middle reaches of the Heihe River}

With the influence of climate change and human activities, the wetland area decreased continuously (Niu et al., 2012; Verones et al., 2013), and it became fragmentation (Gibbes, 2009; Wang et al., 2011; Zhang et al., 2011). It was found that mean patch density, perimeter area ratio and patch shape fragmentation indices increased in different extent, and largest patch index, aggregation index and mean patch size decreased in the previous researches using landscape pattern indices ( $\mathrm{Li}$ and Zhao, 2010; Jiang et al., 2013). It indicated the fragmentation of wetland in the middle reaches of the Heihe River was obvious. In the present study, the wetland area decreased by $7,570 \mathrm{hm}^{2}$ in the past 35 years. The percentage of core wetland decreased by $12.8 \%$, while the perforated, edge and patch wetlands increased by $0.8 \%, 3.1 \%$ and $8.9 \%$, respectively. Therefore, the present study not only examined the decline of wetland area and fragmentation status, but also illustrated the fragmentation process spatially.

With a variable and unpredictable flow course, the wetland spatial distribution patterns of the Heihe River changed from 1975 to 2010. Larger areas of the core wetlands mainly transformed into non-wetlands and edge wetlands, a certain number of edge wetlands and perforated wetlands transformed into patch wetland, and quite a number of patch wetlands transformed into non-wetlands (Table 5). This result indicated that the fragmentation process in the middle reaches of the Heihe River is core wetland $\rightarrow$ perforated or edge wetland $\rightarrow$ patch wetland or non-wetland. The result also showed that the arid inland river wetlands have strong changeable characteristics with the flow variability (Zhou et al., 2006;
Zhao et al., 2009). Significant wetland fragmentation appeared during 1975 to 2010 in the middle reaches of the Heihe River, which may results from climate change and human activity (Niu et al., 2012). Quantification driving factors should be researched in the future study.

\section{Conclusions}

The wetland fragmentation in the Heihe River was clarified between wetland and non-wetland and among wetland fragmentation types by the type change tracker model. The wetland fragmentation model on the pixel level performed well than the traditional wetland fragmentation analysis on the landscape and patch levels. Traditional method such as area frequency statistics, fractal dimension and diversity index integrating with the Chi-square distribution normalized scale variance, performed well in the scale analysis of the wetland fragmentation in the arid inland river. The suitable scale for the type change tracker model ranged from $150 \mathrm{~m} \times 150 \mathrm{~m}$ to $450 \mathrm{~m} \times 450 \mathrm{~m}$, and the optimum scale was $250 \mathrm{~m} \times 250 \mathrm{~m}$ in the middle reaches of the Heihe River. The wetland fragmentation intensified in the past 35 years in the middle reaches of the Heihe River, the total wetland and core wetland decreased by $23.2 \%$ and $12.7 \%$, while that of edge, perforated and patch wetland increased. The arid inland river wetlands are quite variable, and the conversion among four types of fragmentation and non-wetland occurred. The research on conversion among wetland fragmentation types not only illuminates the fragmentation dynamics, but also would enhance the driving mechanism analysis in the future.

\section{Acknowledgements}

The research is supported by the National Natural Science Foundation of China $(41261047,41201196,41271133)$ and the Youth Teacher Scientific Capability Promoting Project of Northwest Normal University (NWNU-LKQN-11-11).

\section{References}

Chen Y, Zhang D Q, Sun Y B, et al. 2005. Water demand management: a case study of the Heihe River Basin in China. Physics and Chemistry of the Earth, Parts A/B/C, 30(6): 408-419.

Civco D L, Hurd J D, Wilson E H, et al. 2002. Quantifying and describing urbanizing landscapes in the northeast United States. Pho- 
togrammetric Engineering and Remote Sensing, 68(10): 1083-1090.

Costanza R, d'Arge R, de Groot R, et al. 1997. The value of the world's ecosystem services and natural capital. Nature, 387: 253-259.

Deimeke E, Cohen M J, Reiss K C. 2013. Temporal stability of vegetation indicators of wetland condition. Ecological Indicators, 34: 69-75.

Desta H, Lemma B, Fetene A. 2012. Aspects of climate change and its associated impacts on wetland ecosystem functions - a review. Journal of American Science, 8(10): 582-596.

Fang C L, Bao C, Huang J C. 2007. Management implications to water resources constraint force on socio-economic system in rapid urbanization: a case study of the Hexi Corridor, NW China. Water Resources Management, 21(9): 1613-1633.

Fleiss J L, Levin B, Paik M C. 2003. Statistical Methods for Rates and Proportions ( $3^{\text {rd }}$ ed). New Jersey: John Wiley \& Sons, 598-626.

Gibbes C, Southworth J, Keys E. 2009. Wetland conservation: change and fragmentation in Trinidad's protected areas. Geoforum, 40(1): 91-104.

Herold M, Scepan J, Clarke K C. 2002. The use of remote sensing and landscape metrics to describe structures and changes in urban land uses. Environment and Planning A, 34(8): 1443-1458.

Jenkins G A, Greenway M, Polson C. 2012. The impact of water reuse on the hydrology and ecology of a constructed stormwater wetland and its catchment. Ecological Engineering, 47: 308-315.

Jiang P H, Zhao R F, Zhao H L, et al. 2013. Relationships of wetland landscape fragmentation with climate change in middle reaches of Heihe River, China. Chinese Journal of Applied Ecology, 24(6): 1661-1668. (in Chinese)

Lasanta T, Vicente-Serrano S M. 2012. Complex land cover change processes in semiarid Mediterranean regions: an approach using landsat images in northeast Spain. Remote Sensing of Environment, 124: $1-14$.

Lee P, Smyth C, Boutin S. 2004. Quantitative review of riparian buffer width guidelines from Canada and the United States. Journal of Environmental Management, 70(2): 165-180.

Li M S, Zhu Z, Vogelmann J E, et al. 2011. Characterizing fragmentation of the collective forests in southern China from multitemporal Landsat imagery: a case study from Kecheng district of Zhejiang province. Applied Geography, 31(3): 1026-1035.

Li S B, Zhao W Z. 2010. Landscape pattern changes of desert oasis wetlands in the middle reach of the Heihe River, China. Arid Land Research and Management, 24(3): 253-262.

Martínez-López J, Carreño M F, Martínez-Fernández J, et al. 2014. Wetland and landscape indices for assessing the condition of semiarid Mediterranean saline wetlands under agricultural hydrological pressures. Ecological Indicators, 36: 400-408.

Mereta S T, Boets P, Ambelu Bayih A, et al. 2012. Analysis of environmental factors determining the abundance and diversity of macroinvertebrate taxa in natural wetlands of Southwest Ethiopia. Ecological Informatics, 7(1): 52-61.

Miller S J, Wardrop D H. 2006. Adapting the floristic quality assessment index to indicate anthropogenic disturbance in central Pennsylvania wetlands. Ecological Indicators, 6(2): 313-326.

Mitsch W J, Bernal B, Nahlik A M, et al. 2013. Wetlands, carbon, and climate change. Landscape Ecology, 28(4): 583-597.

Moellering H, Tobler W. 1972. Geographical variances. Geographical Analysis, 4(1): 34-50.

Montgomery D R, Dietrich W E. 1992. Channel initiation and the problem of landscape scale. Science, 255(5046): 826-830.

Nabahungu N L, Visser S M. 2011. Contribution of wetland agriculture to farmers' livelihood in Rwanda. Ecological Economics, 71: 4-12.

Nielsen E M, Prince S D, Koeln G T. 2008. Wetland change mapping for the US mid-Atlantic region using an outlier detection technique. Remote Sensing of Environment, 112(11): 4061-4074.

Niemi G J, McDonald M E. 2004. Application of ecological indicators. Annual Review of Ecology, Evolution, and Systematics, 35: 89-111.

Niu Z G, Zhang H Y, Wang X W, et al. 2012. Mapping wetland changes in China between 1978 and 2008. Chinese Science Bulletin, 57(22): 2813-2823.

Riitters K H, Wickham J D, O'Neill R V, et al. 2000. Global-scale patterns of forest fragmentation. Conservation Ecology, 4(2): 3.

Riitters K H, Wickham J D, O'Neill R V, et al. 2002. Fragmentation of continental United States forests. Ecosystems, 5(8): 815-822.

Shalaby A, Tateishi R. 2007. Remote sensing and GIS for mapping and monitoring land cover and land-use changes in the Northwestern coastal zone of Egypt. Applied Geography, 27(1): 28-41.

Shen Z, Xie S Q, Pan C Y. 2008. Probabilities and Statistics. Beijing: Higher Education Press, 135-147. (in Chinese)

Song C C, Wang L L, Guo Y D, et al. 2011. Impacts of natural wetland degradation on dissolved carbon dynamics in the Sanjiang Plain, Northeastern China. Journal of Hydrology, 398(1): 26-32.

Teferi E, Uhlenbrook S, Bewket W, et al. 2010. The use of remote sensing to quantify wetland loss in the Choke Mountain range, Upper Blue Nile basin, Ethiopia. Hydrology and Earth System Sciences Discussions, 7(4): 6243-6284.

Townshend J R G, Justice C O. 1990. The spatial variation of vegetation changes at very coarse scales. International Journal of Remote Sensing, 11(1): 149-157.

van Roon M R. 2012. Wetlands in The Netherlands and New Zealand: optimizing biodiversity and carbon sequestration during urbanization. Journal of Environmental Management, 101: 143-150.

Verones F, Saner D, Pfister S, et al. 2013. Effects of consumptive water use on biodiversity in wetlands of international importance. Environmental Science \& Technology, 47(21): 12248-12257.

Vogt P, Riitters K, Estreguil C, et al. 2007. Mapping spatial patterns with morphological image processing. Landscape Ecology, 22(2): 171177.

Vorpahl P, Moenickes S, Richter O. 2009. Modelling of spatio-temporal population dynamics of earthworms under wetland conditions-an integrated approach. Ecological Modelling, 220(24): 3647-3657.

Wade T G, Riitters K H, Wickham J D, et al. 2003. Distribution and causes of global forest fragmentation. Conservation Ecology, 7(2): 7.

Wang Z N, Huang N, Luo L, et al. 2011. Shrinkage and fragmentation of marshes in the West Songnen Plain, China, from 1954 to 2008 and its possible causes. International Journal of Applied Earth Observation and Geoinformation, 13(3): 477-486.

Wen Q K, Zhang Z X, Xu J Y, et al. 2011. Spatial and temporal change of wetlands in Bohai rim during 2000-2008: an analysis based on sat- 
ellite images. Journal of Remote Sensing, 15(1): 183-200. (in Chinese)

Wilson E H, Sader S A. 2002. Detection of forest harvest type using multiple dates of Landsat TM imagery. Remote Sensing of Environment, 80(3): 385-396.

Wu J G, Shen W J, Sun W Z, et al. 2002. Empirical patterns of the effects of changing scale on landscape metrics. Landscape Ecology, 17(8): 761-782.

Yang M X, Nelson F E, Shiklomanov N I, et al. 2010. Permafrost degradation and its environmental effects on the Tibetan Plateau: A review of recent research. Earth-Science Reviews, 103(1): 31-44.

Young R G, Matthaei C D, Townsend C R. 2008. Organic matter breakdown and ecosystem metabolism: functional indicators for assessing river ecosystem health. Journal of the North American Benthological Society, 27(3): 605-625.

Yue T X, Liu J Y, Jøgensen S E, et al. 2003. Landscape change detection of the newly created wetland in Yellow River Delta. Ecological Modelling, 164(1): 21-31.

Zedler J B, Kercher S. 2005. Wetland resources: status, trends, ecosystem services, and restorability. Annual Review of Environment and Resources, 30: 39-74.

Zhang J, Zhou Y K, Li R Q, et al. 2010. Accuracy assessments and uncertainty analysis of spatially explicit modeling for land use/cover change and urbanization: A case in Beijing metropolitan area. Science China Earth Sciences, 53(2): 173-180. (in Chinese)

Zhang R Q, Zhai H Q, Tang C J, et al. 2009. Spatio-temporal location simulation of wetlands evolution of Yinchuan city based on Markov-CA model. WSEAS Transactions on Information Science and Applications, 6(7): 1145-1154.

Zhang Y R, Gong Z N, Gong H L, et al. 2011. Investigating the dynamics of wetland landscape pattern in Beijing from 1984 to 2008. Journal of Geographical Sciences, 21(5): 845-858.

Zhao C Y, Nan Z R, Cheng G D. 2005. Methods for estimating irrigation needs of spring wheat in the middle Heihe basin, China. Agricultural Water Management, 75(1): 54-70.

Zhao J, Chen X, Bao A M, et al. 2009. A method for choice of optimum scale on land use monitoring in Tarim River Basin. Journal of Geographical Sciences, 19(3): 340-350.

Zhao R F, Chen Y N, Zhou H R, et al. 2009. Assessment of wetland fragmentation in the Tarim River Basin, western China. Environmental Geology, 57(2): 455-464.

Zheng Q H, Luo G P, Zhu L, et al. 2010. Prediction of landscape patterns in Ili River Delta based on CA-Markov model. Chinese Journal of Applied Ecology, 21(4): 873-882. (in Chinese)

Zhou H R, Xiao D N, Zhou K F. 2006. Corridor effect of the spatial changes of landscape patterns in arid areas: a case study of the river corridor areas in the middle and lower reaches of Tarim River. Chinese Science Bulletin, 51(1): 82-91.

Zhu G F, Su Y H, Feng Q.2008. The hydrochemical characteristics and evolution of groundwater and surface water in the Heihe River Basin, northwest China. Hydrogeology Journal, 16(1): 167-182. 